\section{ANENCEFALIA, TROMBOSE E ANTICORPOS ANTICARDIOLIPINA}

A síndrome antifosfolipídica (SAF) é uma trombofilia comum em adultos jovens'. Uma eventual associação de anticorpos antifosfolípides (AAF) com anomalias fetais é matéria polêmica. É de interesse o caso de uma gestante anticorpo anticardiolipina (AAC)-positiva na qual uma trombose venosa profunda (TVP) sucedeu um aborto terapêutico por anencefalia.

A paciente, de 24 anos de idade, foi submetida a uma ecografia obstétrica de rotina com 12 semanas de gravidez. $\bigcirc$ exame revelou anencefalia. Um aborto terapêutico foi autorizado pelo Juizado local. Os achados macroscópicos incluíram anencefalia e spina bifida. Três dias após a interrupção, a paciente desenvolveu TVP de membro inferior esquerdo. Tratamento com heparina subcutânea foi efetivo. Níveis baixos de IgG AAC ( I 8,4 GPL) e moderados de IgM AAC (36,2 MPL) foram detectados'. Seis meses depois, o teste para AAC foi negativo. A paciente, sob anticoagulação oral desde o episódio de TVP, encontra-se bem no momento.

Embora a paciente não preencha os critérios atuais para SAF', uma forma provável e transitória da doença pode ser admitida. Uma relação causa-efeito de AAC maternos com anencefalia é de difícil confirmação, entretanto. A presença de AAC pode, potencialmente, ter decorrido do estado de pós-interrupção gestacional.

A associação de AAF com anomalias fetais é polêmica. Em estudo controlado de 40 mães AAC-positivas, a ocorrência do anticorpo se associou a abortos prévios e também a defeitos ventriculares septais ${ }^{2}$. Uma paciente AAF-positiva apresentou histórico de abortos recorrentes e recém-natos com atresia renal e hipogenesia oromandibular ${ }^{3}$. Em outro relato, uma paciente lúpica AAC-positiva, tratada com ácido acetil-salicílico durante a gestação, gerou um menino com deformidades de vértebras torácicas ${ }^{4}$.

Digno de nota, trombose associada à AAC não foi, até o momento, reportada em pacientes cuja interrupção da gravidez tenha decorrido por anencefalia. No entanto, a escassez de relatos ainda não permite definir uma associação de AAF com malformações congênitas. As implicações clínicas e bioéticas da eventual presença de AAF em gestantes de fetos anencéfalos constitui assunto aberto a debate.

Felix Trentin Filho Henrique luiz Staub Porto Alegre - RS

\section{Referências}

I.Wilson WA, Gharavi AE, Koike T, Lockshin MD, Branch DW, Piette JC, et al. International consensus statement on preliminary classification criteria for definite antiphospholipid syndrome. Arthritis Rheum 1999:42: | 309-I | .

2.Kowal-Vern A, Fisher SG, Muraskas J, Jandreski MA, Gianopoulos JG, Husain A. Placental pathological conditions in anticardiolipin antibody positive women whose infants had congenital heart defects. Perinatology | 996; | 6:268-7|

3.Coulam CB. Hypothesis: antiphospholipid antibodies associated with congenital abnormalities? Early Pegnancy 1997;3: 109-12.

4.Chakravarty K, Merry P. Anticardiolipin syndrome, aspirin therapy and fetal malformation. Lupus 1993;2:61-2.

\section{CORREÇÃO VIDEOLAPAROSCÓPICA DAS HÉRNIAS INGUINAIS}

Em relação ao artigo "A videolaparoscopia na hérnia inguinal deve ser rotineira?", publicado na secção "À Beira do Leito" da Rev Assoc Med Bras 2005; 5 I(5):243, tecemos algumas considerações.

As vantagens da hernioplastia inguinal videolaparoscópica sobre a técnica convencional estão bem estabelecidas na literatura médica: menos dor pós-operatória, retorno mais célere às atividades habituais e maior satisfação do paciente.

Rutkow estima que, em 2003, nos EUA, de aproximadamente 800.000 reparos de hérnia, |4\% foram feitos por videolaparoscopia, 37\% por Lichtenstein, 34\% plug repairs, $8 \%$ foram outros reparos com tela e somente $7 \%$ reparos sem uso de prótese'.

As explicações para o menor número de correções videolaparoscópicas ( $14 \%$ ), conforme Arregui e Young, estão relacionadas com o menor reembolso pago aos procedimentos videolaparoscópicos nos EUA, 15,8\% a menos na hérnia primária e $12,4 \%$ na recidivada em relação aos procedimentos abertos. Além disso, deve-se considerar a relativa facilidade do reparo aberto e não existência de um treinamento adequado durante as residências e fellowships em cirurgia nos reparos videolaparoscópicos².

Atualmente, há uma tendência mundial de utilização rotineira de tela para correção de hérnias inguinais no adulto. Em metaanálise que avaliou 58 ensaios clínicos com II . I 74 pacientes, (The EU Trialist Collaboration), o uso de tela demonstrou reduzir o risco de recorrência, redução no tempo de hospitalização, redução de dor pós-operatória na técnica aberta e recuperação mais rápida ${ }^{3}$.

Historicamente, todas as novas técnicas de correção de hérnia inguinal encontraram resistência, mesmo o reparo de Lichtenstein, que atualmente é o mais utilizado.

Segundo Richards, Quinn e Fitzgibbons, quatro avanços na metade final do século $X X$ contribuíram significativamente para a diminuição da morbidade e diminuição da recorrência: uso de próteses, aceitação ampla do conceito de tension-free, possibilidade de uso do espaço pré-peritoneal na correção das hérnias e a terapêutica videolaparoscópica ${ }^{4}$.

As complicações em geral são as mesmas, tanto nos reparos abertos como nos videolaparoscópicos, embora o potencial para lesões mais graves seja maior na abordagem videolaparoscópica. Isto reflete a curva de aprendizagem e o pobre ensinamento da técnica². 